\title{
Engineering Titanium for Improved Biological Response
}

\author{
C. Orme, J. Bearinger, E. Dimasi, J. Gilbert
}

\section{January 23, 2002}

U.S. Department of Energy

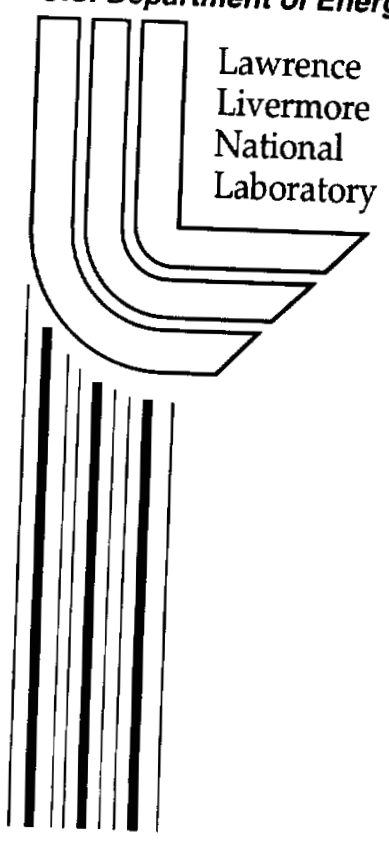




\section{DISCLAIMER}

This document was prepared as an account of work sponsored by an agency of the United States Government. Neither the United States Government nor the University of California nor any of their employees, makes any warranty, express or implied, or assumes any legal liability or responsibility for the accuracy, completeness, or usefulness of any information, apparatus, product, or process disclosed, or represents that its use would not infringe privately owned rights. Reference herein to any specific commercial product, process, or service by trade name, trademark, manufacturer, or otherwise, does not necessarily constitute or imply its endorsement, recommendation, or favoring by the United States Government or the University of California. The views and opinions of authors expressed herein do not necessarily state or reflect those of the United States Government or the University of California, and shall not be used for advertising or product endorsement purposes.

This work was performed under the auspices of the U. S. Department of Energy by the University of California, Lawrence Livermore National Laboratory under Contract No. W-7405-Eng-48.

This report has been reproduced directly from the best available copy.

Available electronically at http: //www.doc.gov/bridge

Available for a processing fee to U.S. Department of Energy

And its contractors in paper from

U.S. Department of Energy

Office of Scientific and Technical Information

P.O. Box 62

Oak Ridge, TN 37831-0062

Telephone: (865) 576-8401

Facsimile: (865) 576-5728

E-mail: reports@adonis.osti.gov

Available for the sale to the public from

U.S. Department of Commerce

National Technical Information Service

5285 Port Royal Road

Springfield, VA 22161

Telephone: (800) 553-6847

Facsimile: (703) 605-6900

E-mail: orders@ntis.fedworld.gov

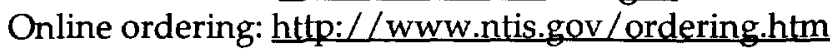

\section{OR}

Lawrence Livermore National Laboratory

Technical Information Department's Digital Library

http://www.llnl.gov/tid/Library.html 
Final Report for LDRD 00ERI-006:

Engineering Titanium for Improved Biological Response

Principal Investigator: Christine Orme (LLNL)

Co-investigators:

- Jane Bearinger (LLNL, Northwestern University)

- Elaine Dimasi (Brookhaven National Laboratory)

- Jeremy Gilbert (Syracuse University)

\section{Introduction}

The human body and its aggressive environment challenge the survival of implanted foreign materials. Formidable biocompatibility issues arise from biological, chemical, electrical, and tribological origins. The body's electrolytic solution provides the first point of contact with any kind of implant, and is responsible for transport, healing, integration, or attack. Therefore, determining how to successfully control the integration of a biomaterial should begin with an analysis of the early interfacial dynamics involved.

One of the most remarkable systems in the body is bone remodeling. Even in a purely natural setting, a complicated feedback system of solution chemistry, $\mathrm{pH}$, ions, and solubility exists. The introduction of a fixation device instantly confounds this system. The body is exposed to a range of voltages, and wear can bring about significant shifts in potentials across an implant. In the environment of a new implant the solution $\mathrm{pH}$ becomes acidic, ionic concentrations shift, cathodic currents can lead to corrosion, and oxygen levels can be depleted; all of these impact the ability of the implant to retain its protective oxide layer and to present a stable interface for the formation of a biolayer.

Titanium has been used in orthopedic and maxilofacial surgery for many years due to its reputation as being biocompatible and its ability to osseointegrate. Osseointegration is defined as direct structural and functional connection between ordered, living bone, and the surface of a load carrying implant. Brånemark ${ }^{1}$ discovered this phenomenon in the 60's while examining titanium juxtaposed to bone. The mechanism by which titanium and its passivating oxide encourage osseosynthetic activity remains unknown. However in general terms the oxide film serves two purposes: first to provide a kinetic barrier that prevents titanium from corroding and second to provide a substrate that allows the constituents of bone (calcium phosphate crystals, cells, proteins, and collagen) to bond to it.

We believe that the electrochemical environment dictates the titanium dioxide surface atomic structure and the biological response at an implantation site. To date, most researchers in this area have surgically implanted materials into living organisms and then retrieved the implant after varying amounts of time have elapsed. The virtue of this style of experiment is that the full, correct chemistry of the body acts on the implant. The difficulty with these experiments is that it is then impossible to link cause with effect because too many variables are changing simultaneously. Another difficulty is that changes in the very early times are missed. The purpose of these experiments is to visualize the early time response of oxide films to electric fields and to solution variations found in the body near bone. Specifically these studies are meant to understand how chemical and electric stress effect the corrosion resistance and the formation of a biolayer. Instead of performing in vivo experiments as described above, our strategy uses titanium manufactured for implants and places these samples in controlled, simplified, solutions that mimic the electrolytic environment near the bone. We use an electrochemical atomic force microscope to image the real-time dynamics of the substrate in 
solution as the oxide film is growing. While imaging we apply a potential between a reference electrode and the titanium substrate which creates a driving force for oxide growth and dissolution. We simultaneously collect the transient current that flows across the oxide layer and use step impedance polarization spectroscopy to determine electrical properties of the oxide layer. We will look for films that successfully nucleate the calcium phosphate crystals that comprise the inorganic phase of bone, but do not corrode under these challenging conditions. The goal is to correlate corrosion resistance and biolayer adhesion with oxide film morphology and material properties in physiological environments. Research is geared towards answering the following questions:

- How do the material properties such as structure, donor density, and open circuit potential (OCP) change, as the oxide is grown?

- How does the surface morphology correlate with the material properties?

- How do these changes impact nucleation of calcium phosphate or adhesion of cells?

\section{Techniques}

Most types of probes and tests that are used to either elucidate structural properties or to convey information on morphology and electrical properties are either 1) not conducive to working in an aqueous environment, 2) not indicative at a microscopic scale, or 3) don't address the full range of potentials experienced in the body. Concurrently, there is a lack of data which relates this information to biological systems where the subsequent adhesion of biological elements is key to biocompatibility.

The tools to be used for this experimentation consist of Electrochemical Atomic Force Microscopy (EC AFM), Step Polarization Impedance Spectroscopy (SPIS) ${ }^{2}$, and Surface Xray Diffraction (SXRD). Ideally, this exploration of material properties will lead to methods to engineer titanium oxide to target or elicit specific responses by the body (i.e. kinetics, binding, and synthesis).

\section{Electrochemical environment}

The general corrosion response of titanium in an aqueous environment can be related to $\mathrm{pH}$ and applied overpotential ${ }^{3}$. Consequently, regions of passivation, corrosion, and immunity may be predicted. In the largest and most biologically relevant region near neutral $\mathrm{pH}$ and no applied field, titanium is in equilibrium with an oxide film that provides a stable, passivating layer. However, in the environment of a wound the $\mathrm{pH}$ becomes much more acidic bringing it closer to a corrosive regime. In addition, fretting of the implant material can cause the local open circuit potential to shift by as much as $-1 \mathrm{~V}$. This can bring the material into the cathodic corrosion regime and cause subsequent pitting.

In our studies we fix $\mathrm{pH}$ and focus on the effect of potentials to study how naturally occurring fields in the body affect the oxide. While anodic potentials are thought to strengthen the oxide barrier, it is proposed that even slight cathodic potentials may in fact weaken the oxide, accelerating corrosion kinetics.

\section{FY00 Results}

In FY00 our studies concentrated on the morphology and electrochemical properties of the TiO2 layer in phosphate buffered saline solutions. The first set of experiments describes the hydration of the oxide film. The second set of experiments describes the current-voltage characteristics and how they relate to morphological changes. We compare these results for different 
orthopedic materials (commercially pure Ti and CP64) as well as the model system Ti sputtered on Si.

\section{The hydration of Titanium}

In figure 1 we show force microscope images of the same oxide film before and after immersion in phosphate buffered saline. The dry substrate shows well separated oxide domes. Immediately upon immersion, these domes grow laterally and impinge upon one another. The domes coarsen over time. After drying, the surface resembles the original starting surface. While not identical, several features can be correlated in the two dry images. The changes in morphology for dry versus wet samples imply that vacuum techniques such as XPS or SEM have limited application in characterization of the oxide in the native, hydrated state as compared to in-situ experiments.

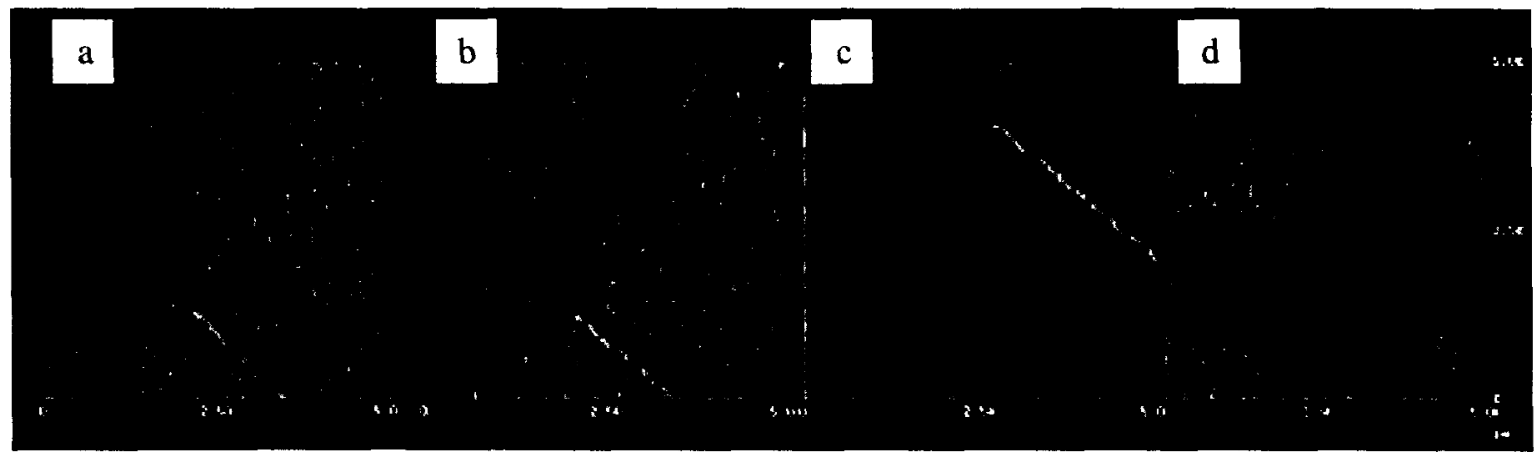

Figure 1: The morphology of an oxide film before during and after immersion in a PBS solution. All images show a $5 \mu \mathrm{m} \times 5 \mu \mathrm{m}$ area at the same grain boundary. a) A dry CPTi sample showing well separated oxide domes. b) The same spot minutes after immersion in a phosphate buffered saline solution. The oxide domes have grown laterally, impinging on one another. c) After 18 hours in solution the oxide domes have coarsened and now have 5 times the surface area. d). The surface after removing from solution and drying with a stream of nitrogen gas. These images clearly show that the surface is not the same dry and wet. This implies that surface measurements taken in vacuum lose information about the hydrated surface that may be important for implant characterization.

While the lateral growth and coarsening of the oxide domes was seen on all samples examined, the rate of this growth could be controlled by the overpotential. The rate of hydration can be quantified by taking a succession of images over time and measuring the areas of the domes. Under open circuit potential (OCP) conditions, the oxide domes of commercially pure titanium expand at a rate of $1098 \mathrm{~nm}^{2} / \mathrm{min}$. Application of a $-1 \mathrm{~V}$ overpotential decreases the kinetic growth rate to $185 \mathrm{~nm}^{2} / \mathrm{min}$, six times slower. In this way the dome diameter or surface roughness can be controlled which may in turn, effect subsequent biolayer adhesion.

\section{Current-Voltage characteristics and morphology}

Bone can abrade titanium oxide on an implant, resulting in an OCP drop close to $1 \mathrm{~V}$. To mimic this effect we examined the $\mathrm{TiO}_{2}$ morphology and electrical response in the range of $-1 \mathrm{~V}$ to $+1 \mathrm{~V}$. Both the imaging and electrical response were monitored simultaneously. As the voltage was ramped in the positive direction, early (oxide) resistance increased and capacitance decreased both consistent with oxide film growth. Although the plots are hysteretic, the electrical properties approach starting values when voltage is looped back down. In contrast, the oxide 
dome size continually increases with voltage, but does not decrease with voltage. These results are summarized in figure 2 . Though independence of morphology and electrical properties was initially unexpected, it can be explained by $\mathrm{TiO}_{2}$ 's classification as an n-type semiconductor. Thus, the oxide grows and changes at the metal/oxide interface, not the oxide/solution interface. The metal/oxide interface is in fact changing, but the layers of oxide on top of the interface mask the electrochemically-noted effect. The decoupling between electrical response and morphology may in fact result in a more stable interface between an implant and the biological milieu.

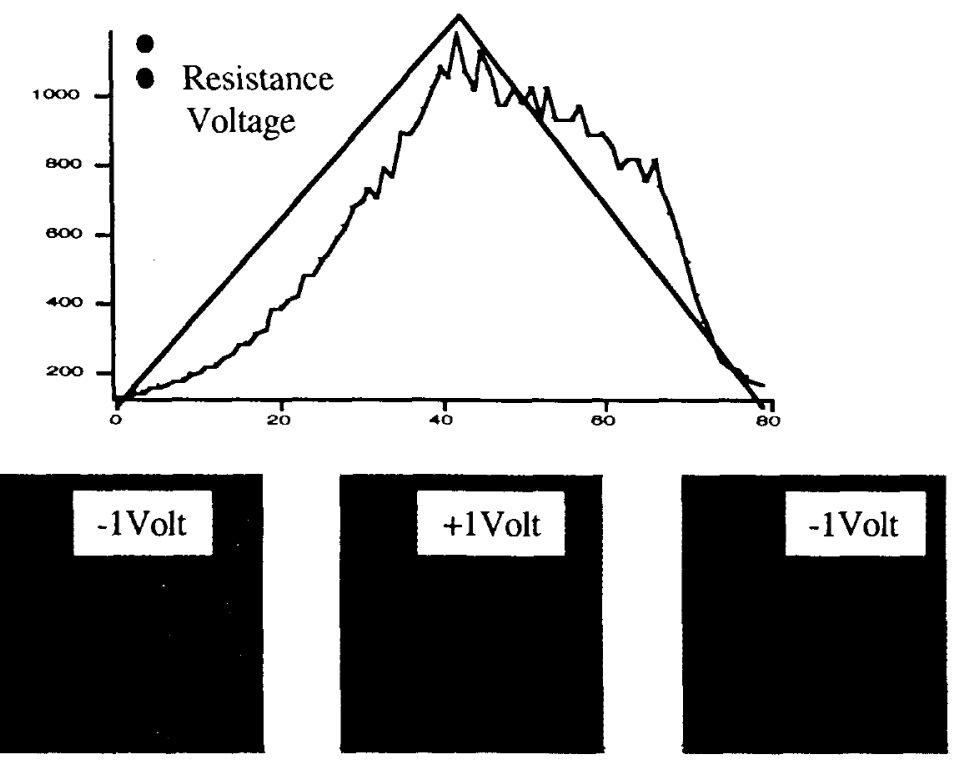

Figure 2: The electrical properties return to close to their starting values as the voltage is ramped up and down. The morphology however is unidirectional. The electrical properties and the surface morphology are decoupled; this may produce a more stable interface for the adsorbed biolayer.

\section{Comparison of Current-Voltage characteristics between different Ti substrates}

Orthopedic implants typically use an alloy of titanium, aluminum and vanadium rather than the pure titanium used in dental implants. To compare these we looked at the morphology and I-V characteristics of both of these materials as well as a model system Ti sputtered on silicon.

Figure 3 shows images of the starting substrates. The morphological differences are summarized in the figure caption. The dome evolution was qualitatively the same for the three substrates examined (CPTi, CP64, Ti/Si). All substrates have oxide domes that grow and coarsen with exposure to aqueous solutions and the hydration process is independent of the electrical properties. The one difference is that the regions of b-phase on the alloy (CP64) are flat, implying that the oxide is conformal or that the oxide domes are too small and inter-grown to resolve with an AFM tip. 

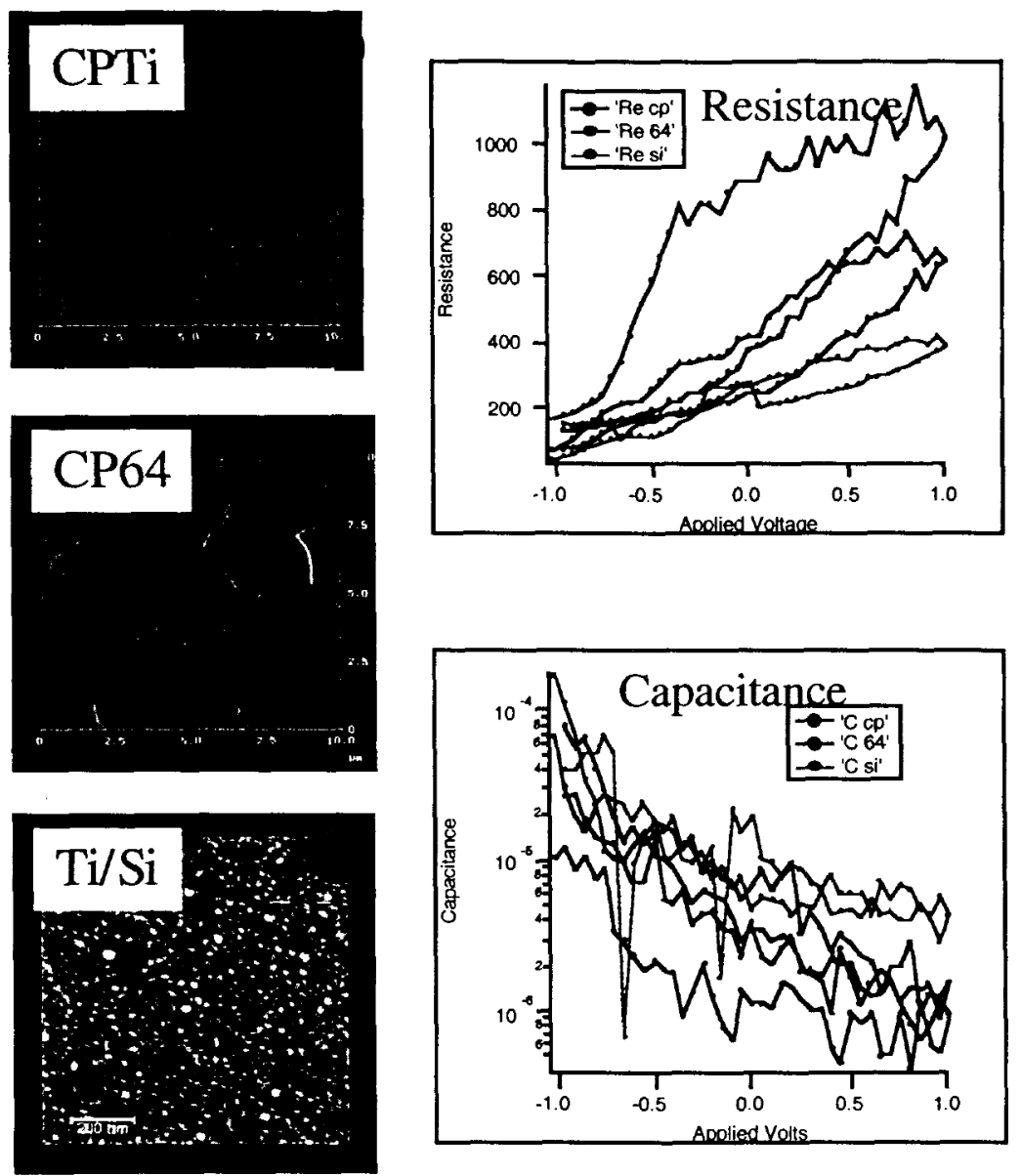

Figure 3: A comparison between different titanium substrates. Commercially pure titanium (CPTi) is used in dental implants. It is composed of $50 \mu \mathrm{m}$ hcp grains ( $\alpha$-phase). Shown is the junction of three grains. The alloy, titanium 6 aluminum 4 vanadium (CP64), has two main phases hcp ( $\alpha$-phase) and vanadium rich bcc ( $\beta$-phase). The $\beta$-phase is more resistant to acidic etching and stands out in the image. Also shown is the model system titanium sputtered onto a silicon substrate. This image was taken using a carbon nanotube tip because the oxide domes are smaller than the radii of standard AFM tips. The resistance and capacitance data is derived from the current transients that occur when the voltage is stepped. The general trends for all three samples are consistent with oxide film growth (naively, $\mathrm{R} \propto \mathrm{d}$ and $\mathrm{C} \propto 1 / \mathrm{d}$ ). This data suggests that $\mathrm{CPTi}$ has the greatest corrosion resistance. This is somewhat surprising because the Ti64 alloy is more resistant to acid etching due to the vanadium rich grains. 
The electrical properties of the three substrates were also qualitatively similar; the resistance and capacitance data are consistent with oxide growth as the voltage is ramped in the anodic direction. This data suggest that CPTi has the greatest resistance to corrosion of the three materials examined.

\section{Milestones FY00}

- Developed system to simultaneously perform ECAFM and impedance measurements.

- Imaged dynamic hydration events in situ at the micron scale.

- Developed control over hydration kinetics of Ti/TiO2 in aqueous solution.

- Measured electrochemical properties of oxide films as a function of voltage

- Discovered decoupling of electrical properties and surface morphology.

\section{Work proposed for FY01}

Last year we proposed to work in three primary areas (taken verbatim from FY01 proposal).

Formation of the biolayer (mineralization and protein adsorption)

Our focus for upcoming years, is to understand how to manipulate the biolayer formation. We will pursue this by looking at how calcium phosphate crystals nucleate and how bone proteins adsorb on $\mathrm{TiO}_{2}$ surfaces. We will also look at the interplay between these two adsorbing materials. We are seeking to control the mineral phase, adhesion, kinetics, and coverage through a combination of solution chemistry, potential, and surface preparation.

\section{Mimic wound healing:}

We will also investigate the effects of dilute hydrogen peroxide on the morphology and electrical properties of $\mathrm{TiO}_{2}$ to address the question of how implants respond during the initial stages of implantation (or subsequent wound healing). We will characterize the differences with and without hydrogen peroxide and then look at how the differences might effect biolayer formation.

\section{Structural characterization}

We will characterize the oxide film using surface xray diffraction. These experiments will identify the $\mathrm{TiO}_{2}$ thickness, $\mathrm{TiO}_{2}$ structure, and near surface ordering of calcium ions during

a

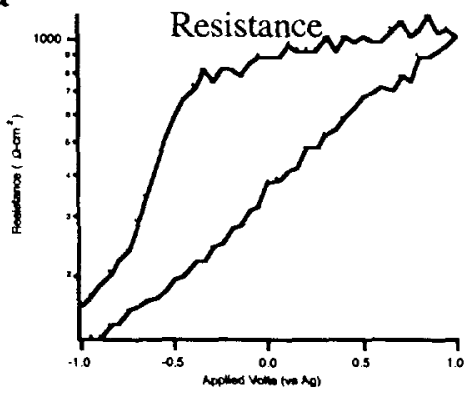

c

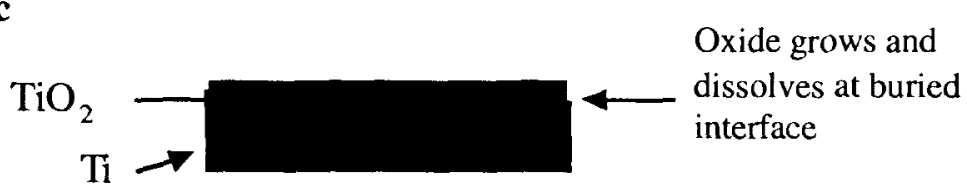

Figure 4: The electrical response of commercially pure titanium (CPTi) in a phosphate buffered saline solution (PBS). As the voltage is increased (a) the resistance increases and (b) the capacitance decreases consistent with oxide

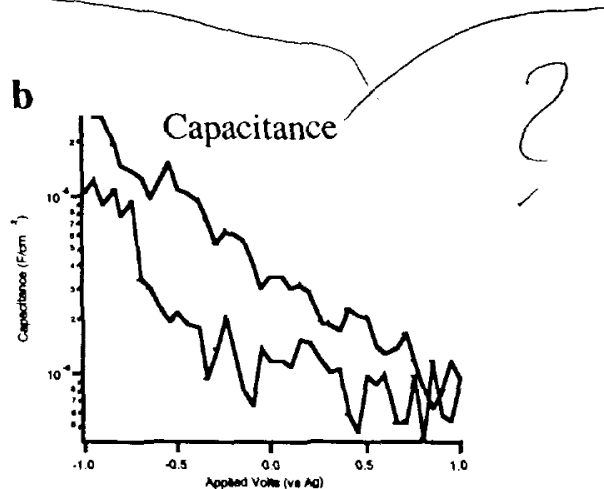

Oxide grows and dissolves at buried interface 
morphology of the oxide changes to permit higher diffusion rates. The oxide resistance (shown in figure 5) should reflect this. For Ti64 the resistance (and capacitance) data remains largely unchanged as compared to PBS. However for CPTi the resistance which is approximately linear with voltage in PBS (fig 4a) becomes independent of voltage in hydrogen peroxide containing solutions. This data suggests that additional $\mathrm{TiO} 2$ is not formed under anodic conditions but rather that a new, low-resistance, porous form of oxide grows. In summary:

- Charge transfer increases by an order of magnitude as compared to phosphate buffered saline (PBS).

- The oxide resistance of commercially pure titanium (CPTi) becomes independent of voltage in hydrogen peroxide containing solutions.

- The oxide resistance of alloyed titanium (Ti64) is unchanged as compared to pure PBS. We propose that CPTi forms a porous adlayer of Ti-peroxy compounds while Ti64 does not.

a

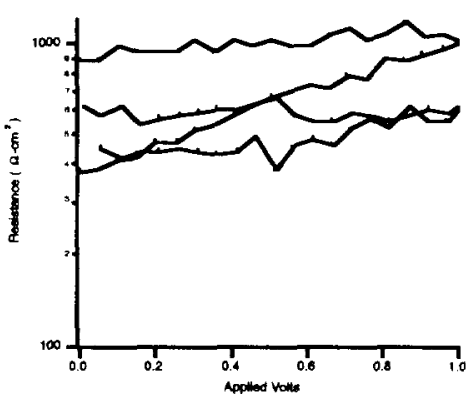

C

$$
\text { Ti-Peroxy }
$$

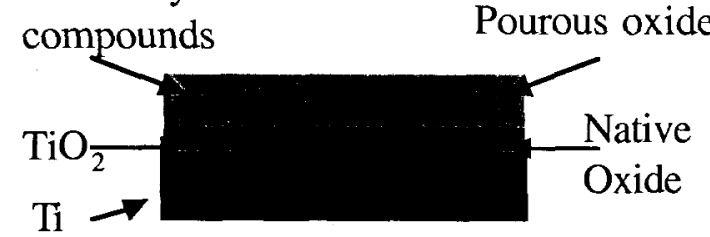

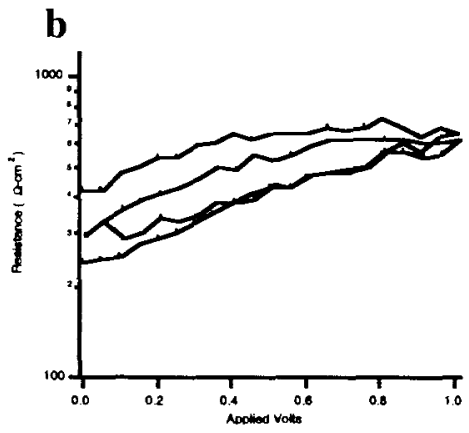

Pourous oxide

Figure5: Resistance as a function of applied voltage in the range $0-1 \mathrm{~V}$. The blue curve is in phosphate buffered saline(the control) and the red curve is phosphate buffered saline with $30 \mathrm{mM} \mathrm{H2O}$. (a) The response of the CPTi sample is distinctly different in $\mathrm{H} 2 \mathrm{O} 2$ bearing solutions (red) as compared to the PBS solution (blue). By contrast, the alloy Ti64 (b) appears unchanged by the presence of $\mathrm{H}_{2} \mathrm{O}_{2}$. We propose that the CPTi forms an adlayer of porous, non-stoichiometric $\mathrm{Ti}$ oxide in the presence of $\mathrm{H} 2 \mathrm{O} 2$ rather than growing more $\mathrm{TiO} 2$ as it did in PBS.

\section{Structural characterization using surface $x$-ray diffraction}

Because the dental and orthopedic samples are both polycrystalline and macroscopically rough we used more idealized substrates for these studies. For our first run we used titanium sputter deposited onto a silicon substrate. The results are shown in figure 6 . The sharp peaks in the interference pattern are due to slight modulations in the bulk density, due to the preparation of the sample as a titanium "multilayer" formed by successive stages of sputtering. The minimum at $q_{s}=0.1 A^{\wedge}-1$ is probably due to the oxide. But since the bulk peaks dominate the reflectivity and cannot be modeled in a simple way, it is not feasible to determine the structure of the native oxide layer at the surface. 


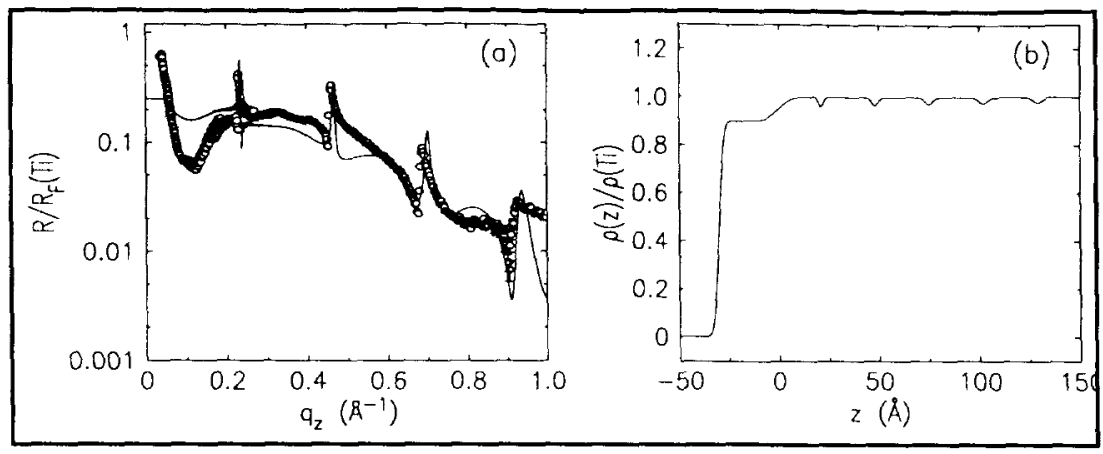

Figure 6: (a) circles: Fresnel-normalized reflectivity of Ti/Si sample. line: calculated reflectivity from model in (b). (b) model surface-normal density profile, with the zero defined at the $\mathrm{Ti}-\mathrm{TiO} 2$ boundary. The thin oxide is masked by density variations in the substrate material.

For the second run we chose single crystal rutile, the most stable polymorph of titanium. Figure 7 shows the reflectivity of the rutile (001) surface, at low angle and near the (002) bragg peak. The solid line shows the scattering from a perfect truncation of the crystal structure. The data exhibit a roughened, reconstructed, and/or relaxed surface structure with essentially no difference between the dry crystal (circles), the crystal in contact with water (triangles), and the crystal exposed to $2 \% \mathrm{H}_{2} \mathrm{O}_{2}$ (diamonds). From AFM experiments we know that the surface is flat (on lateral scales greater than the $10 \mathrm{~nm}$ ) under these conditions.

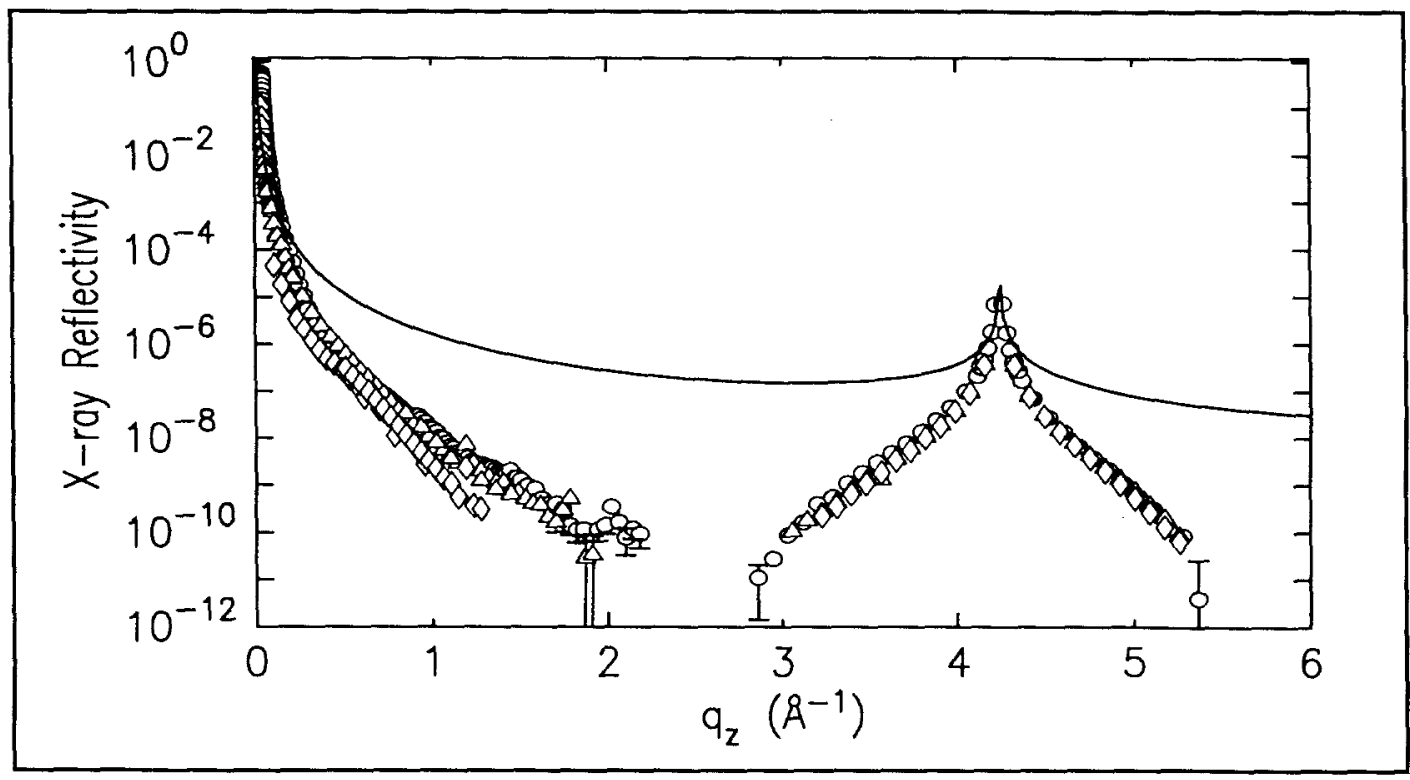

Figure 7: Reflectivity vs wavenumber for the $\mathrm{TiO} 2$ polymorph, rutile (100). The solid line shows the scattering from a perfect truncation of the crystal structure. The data exhibit a roughened, reconstructed, and/or relaxed surface structure with essentially no difference between the dry crystal (circles), the crystal in contact with water (triangles), and the crystal exposed to $2 \% \mathrm{H} 2 \mathrm{O} 2$ (diamonds).

The next run is scheduled for June $23^{\text {rd }}$. The primary goal is to add potentiostatic control to drive the oxidation and calcification process. I will travel to Brookhaven to participate. 
We have identified a suitable substrate and have performed the initial characterization of the surface.

\section{Bio-layer formation}

It has been shown that the AFM can be used to deposit additional $\mathrm{TiO}_{2}$ under the probe when a bias voltage is applied between the tip and the sample. Using this technique we have begun to create patterns of thick and thin oxide (see figure 8 ). In future projects we hope to use these patterns to control the deposition of mineral and protein.

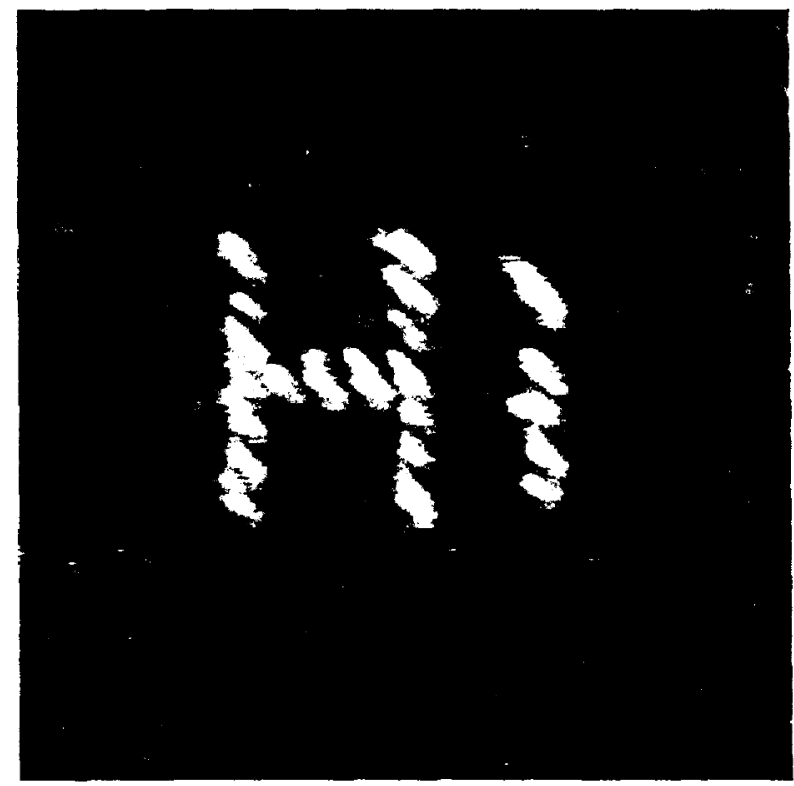

Figure8: AFM image ( $1 \mu \mathrm{m} \times 1 \mu \mathrm{m})$ showing oxide greeting drawn on Tifilm by applying a voltage between the AFM tip and the substrate.

\section{Papers/Grants/Presentations}

"Direct Observation of Hydration of $\mathrm{TiO}_{2}$ on Ti Using Electrochemical AFM: Freely Corroding Versus Potentiostatically Held” Invited paper accepted into Surface Science (2001) (Bearinger, Orme, Gilbert)

Used electrochemical control of nucleation events and general knowledge of mineralization events to write a component of "The role of calcification in vascular dysfunction and disease", PI John Rutledge, UC Davis Medical Center, applied to NIH.

Presented poster of "run l" studies "Surface xray scattering studies of bone mineralization" at Bimineralization Gordon conference 8/2000 (Dimasi, Bearinger, Orme)

\section{FY01 Milestones:}

- Discovered that pure and alloyed titanium responds differently to model surgical wound environment. We propose that pure titanium forms a Ti-peroxy layer while the alloy does not. We will look for structural changes using SXRD.

- Completed surface xray scattering survey of Ti sputtered onto Si and found it unsuitable for studying the oxide layer. 
- Completed surface xray scattering survey of single crystal rutile (100) in air, water, and dilute $\mathrm{H}_{2} \mathrm{O}_{2}$. We will focus on this crystal in future studies.

\section{Personnel and Budget}

The instrumentation (electrochemical AFM, SPIS, SXRD) and select researchers/ collaborators of LLNL are well suited and uniquely positioned to be able to conduct an in-situ study of titanium in the biological environment. Dr. Christine Orme has a background in the physics of evolving surfaces and has extensive experience using the AFM to monitor solution mediated crystal growth. Dr. Elaine Dimasi has a background in physics and performs the surface xray diffraction measurements at Brookhaven National Laboratory. Jane Bearinger has a Ph.D. in bioengineering based upon the research in this LDRD. She currently postdocs at ETH, Zurich but we correspond regularly to complete data analysis and to finish papers. Professor Jeremy Gilbert is a recognized corrosion expert in the field of biomaterials and regularly consults for orthopedics companies.

\section{Summary}

The basic science of this project is significant to biomaterials, environmental containment and cleanup, and engineering materials development. Performance of titanium can be improved by studying:

- electrochemical properties of titanium in aqueous environments

- repassivation of titanium after oxide removal by electrochemical forces

- mineral deposition onto the surface

These issues play a role not only in osseointegration, but also in titanium waste containers on which strongly adherent scales form, and in Naval applications in which corrosion is a problem. The basic science of this proposal feeds into two existing lab programs. The Yucca mountain project is tasked with developing a robust model for passive oxides and the Medical Technologies Program has a general need for competency in biomaterials. Specifically, I have recently started working with the Yucca Mountain to use techniques and expertise developed during the course of this LDRD project to measure oxide evolution and breakdown on alloy (C22) used in waste containers. More generally, by controlling surface treatment, environmental composition and sample potential, and then monitoring surface electrochemistry, composition, and morphology, this study will lead to design strategies that will increase titanium's resistance to dissolution, and accelerate or deter surface nucleation

\section{Auspices:}

This work was performed under the auspices of the U.S. Department of Energy by the University of California, Lawrence Livermore National Laboratory under contract No. W-7405-Eng-48.

\footnotetext{
${ }^{1}$ Brånemark, PI; Breine, U; Adell, R; Hansson, BO; Lindstrom, J; Ohlsson, A, Intra-osseous anchorage of dental prostheses I. Experimental studies, Scan. J. Plast. Reconstr. Surg. 16, 17, 1969.

${ }^{2}$ Gilbert, JL, Step Polarization Impedance Spectroscopy of Implant Alloys in Physiological Solutions, J. Biomed. Mat. Res., 40(2),233, 1998.

${ }^{3}$ Park, JB; Lakes, RS, In Biomaterials: an Introduction, p.104, Plenum Press, NY, NY, 1992.
} 